\title{
Feasibility of Supersonic Aircraft Concepts for Low-Boom and Flight Trim Constraints
}

\author{
$\mathrm{Wu} \mathrm{Li}{ }^{1}$ \\ NASA Langley Research Center, Hampton, Virginia 23681, USA
}

\begin{abstract}
This paper documents a process for analyzing whether a particular supersonic aircraft configuration layout and a given cruise condition are feasible to achieve a trimmed lowboom design. This process was motivated by the need to know whether a particular configuration at a given cruise condition could be reshaped to satisfy both low-boom and flight trim constraints. Without such a process, much effort could be wasted on shaping a configuration layout at a cruise condition that could never satisfy both low-boom and flight trim constraints simultaneously. The process helps to exclude infeasible configuration layouts with minimum effort and allows a designer to develop trimmed low-boom concepts more effectively. A notional low-boom supersonic demonstrator concept is used to illustrate the analysis/design process.
\end{abstract}

\section{Nomenclature}

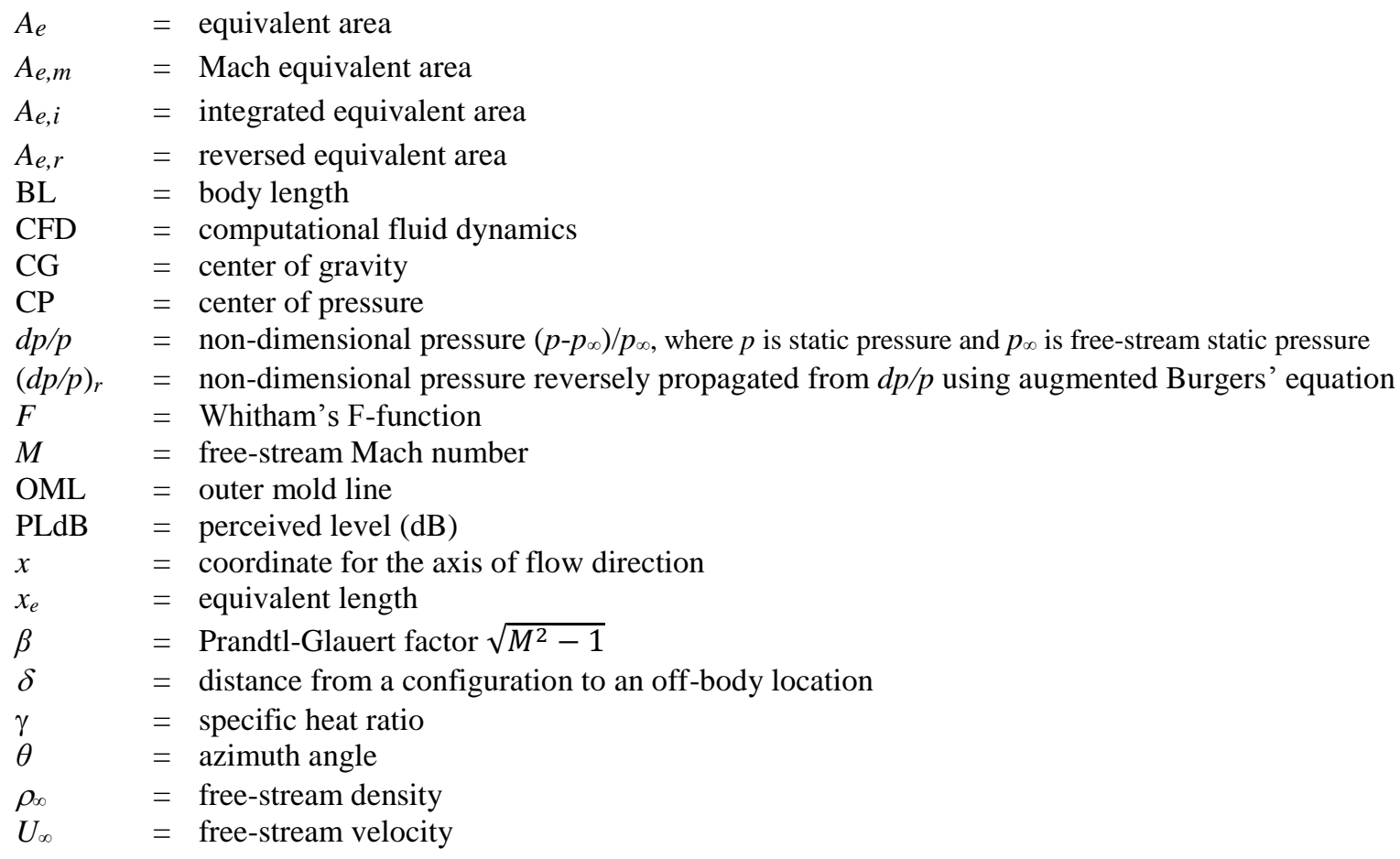

\section{Introduction}

REMENDOUS advances in research related to low-boom supersonic configurations have been made in the past few years. References after 2010 include validation of CFD methods for computing off-body pressure distributions ${ }^{1-10}$ by using novel wind tunnel measurement techniques, ${ }^{11-17}$ new methods for design of low-boom

\footnotetext{
${ }^{1}$ Senior Research Engineer, Aeronautics Systems Analysis Branch, Mail Stop 442
} 
supersonic configurations, ${ }^{18-37}$ and development of low-boom supersonic concepts that include nacelles and some mission constraints. ${ }^{28-41}$

One of the remaining technical challenges in development of low-boom supersonic concepts is the difficulty of knowing when to continue work on the current configuration layout for a trimmed low-boom design and when to move on with a more promising concept. It is not unusual to work on a seemingly promising concept for many months, and then realize that it would be impossible to achieve a trimmed low-boom design by only morphing the OML at the given cruise condition. The flight trim constraint hinders the low-boom potential of a supersonic concept. Here the flight trim constraint is defined as follows: the location of CP is ahead of the most aft CG during the cruise segment[s] for the specified flight mission requirements.

This paper introduces a process for evaluation of any configuration layout as a viable candidate for a trimmed low-boom design at a given cruise condition. By exploring the design space for cruise conditions and the related trim-feasible low-boom targets, one could determine with confidence whether a given configuration layout is feasible to be shaped into a trimmed low-boom design at the specified cruise condition, and if not, what modifications are appropriate to achieve such a design. The modifications considered in this paper involve cruise Mach number, cruise altitude, vehicle length, wing planform, and fuselage/wing/tail shapes.

The key insight behind the feasibility analysis/design process is the validity of an approximation relationship ${ }^{33}$ between the equivalent area defined by Mach angle cuts of a CFD surface solution and the reversed equivalent area ${ }^{29}$ $\left(A_{e, r}\right)$ defined by off-body pressure distribution. Using this approximation, a surrogate model could be built to predict the flight trim constraint violation for a given $A_{e, r}$ target and allows the incorporation of a flight trim constraint in low-boom $A_{e, r}$ targets. By generating a trim-feasible low-boom $A_{e, r}$ target, Ordaz, Geiselhart, and Fenbert ${ }^{37}$ successfully developed a trimmed low-boom concept of $108 \mathrm{ft}$ in length, at a cruise Mach of 1.6, a cruise altitude of $51,700 \mathrm{ft}$, and a cruise weight of $21 \mathrm{~K} \mathrm{lbs}$. A trim-feasible low-boom $A_{e, r}$ target allows designers to shape a configuration for a low-boom constraint, while the resulting low-boom design automatically satisfies the flight trim constraint.

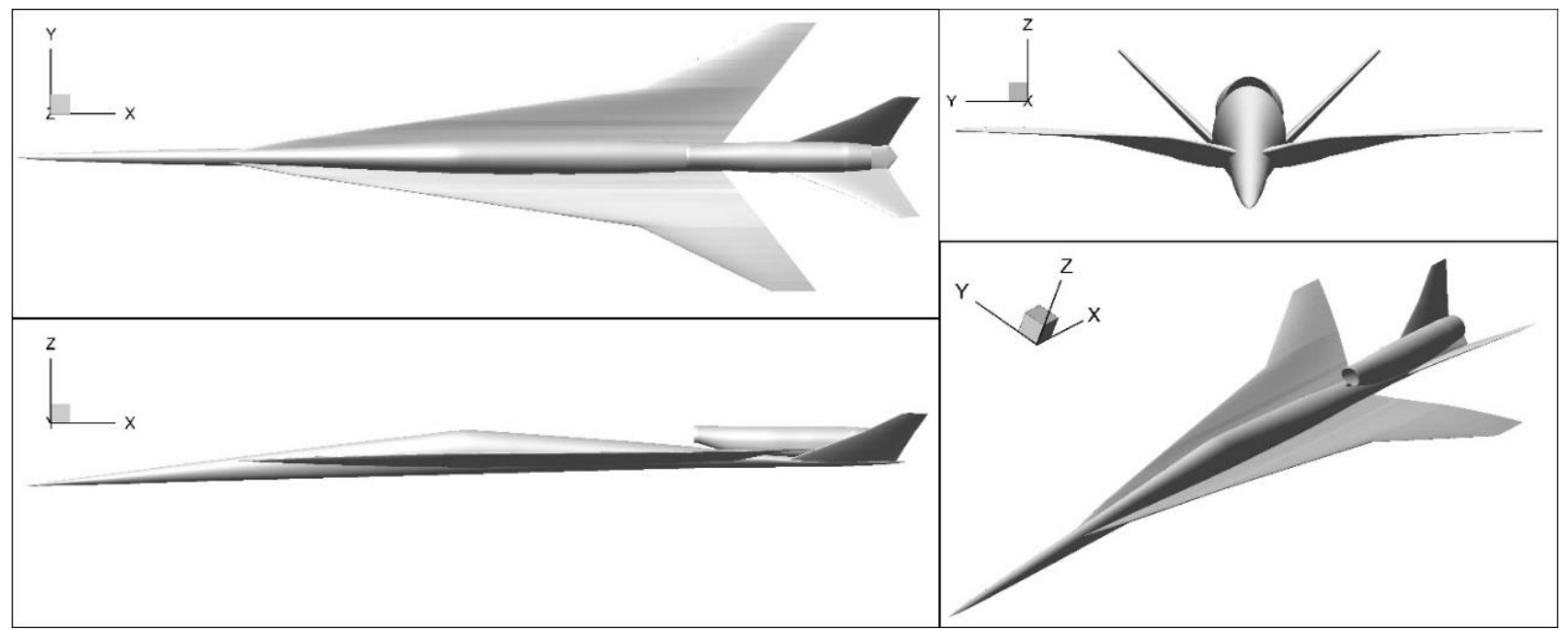

Figure 1. OpenVSP model for a V-tail supersonic low-boom demonstrator concept of $100 \mathrm{ft}$ in length.

A notional low-boom supersonic demonstrator concept (shown in Fig. 1) will be used to explain and illustrate the feasibility analysis/design process. The flight condition is set at a cruise Mach number of 1.5 , cruise weight of $21 \mathrm{~K} \mathrm{lbs}$, and cruise altitude between $45 \mathrm{~K}$ and $55 \mathrm{~K} \mathrm{ft}$. The configuration has a body length (BL) of $100 \mathrm{ft}$ and a single [flow-through] engine. The fuselage satisfies a realistic volume constraint for an existing cockpit and the flow-through nacelle is sized to represent an existing engine for a flight demonstrator concept. Some simple rules for thickness-to-chord ratios of airfoils (such as a thickness-to-chord ratio of 5\% for the tip airfoil) are enforced to avoid unrealistically thin wings. One important geometry constraint for a demonstrator concept (i.e., the fuselage and wing volume constraint for landing gear) is not considered in this study. Vehicle Sketch Pad (OpenVSP) ${ }^{43}$ is used to generate the initial geometry concepts and a shape morphing tool PROTEUS ${ }^{44}$ is used for design changes in CFDbased shape optimization. Analytical methods in FLOPS ${ }^{42}$ are used to estimate CG of the notional concept in this paper. 
Note that uncertainty in CG location could have a detrimental effect on the feasibility analysis/design process. The "as-built" CG can be significantly different from the FLOPS estimate. If the estimate of CG location is far forward of the actual location, then the designer might unnecessarily move the wing forward to satisfy the flight trim constraint. This unnecessary move could lead to a layout that is infeasible with respect to the low-boom constraint. On the other hand, if the CG estimate is far aft of the actual CG location, then the aircraft will be shaped to satisfy the low-boom constraint at the wrong trim condition and the resulting configuration will have to deploy control surfaces (such as flaps) to achieve a trimmed flight. The deployed control surfaces could significantly increase the sonic boom level of the configuration, exceeding the goal PLdB value and making the configuration infeasible for the low-boom constraint.

The off-body pressure calculations use the automated Cart $3 \mathrm{D}^{45}$ analysis process described in Ref. 46 . Figure 2 shows the Cart3D contour plots for an OpenVSP geometry model. The propagation of $d p / p$ at 3 body lengths through the standard atmosphere to the ground is computed using $\mathrm{sBOOM},{ }^{47}$ a wave propagation code using augmented Burgers' equation.

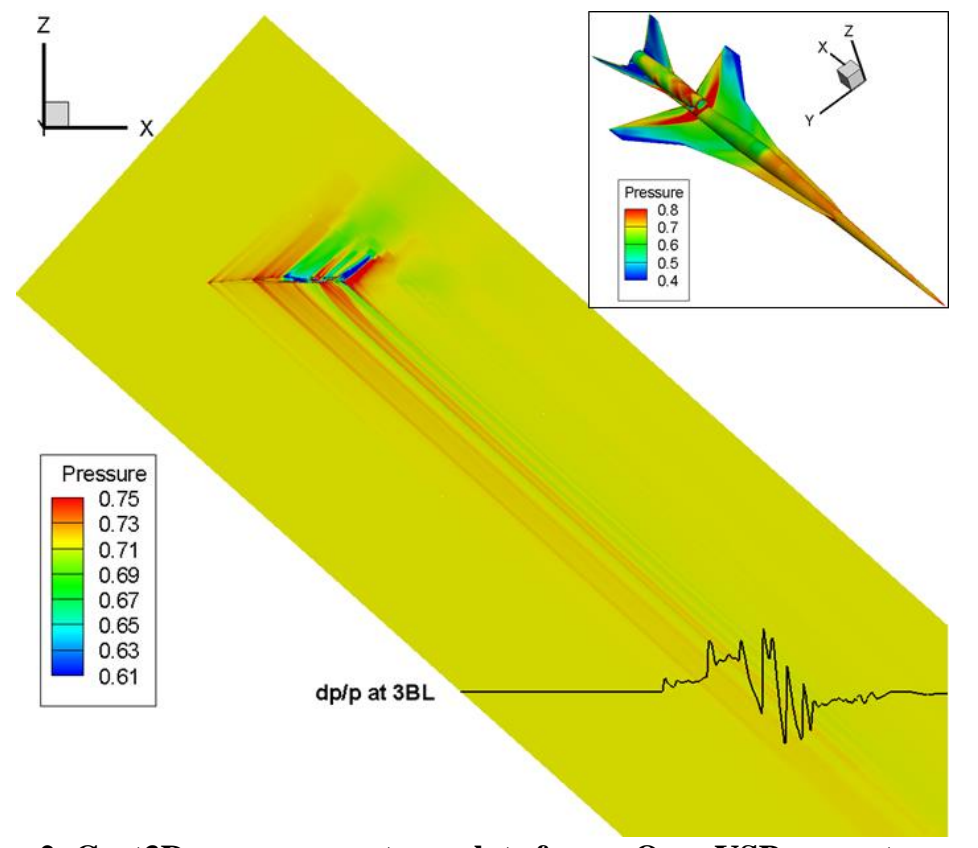

Figure 2. Cart3D pressure contour plots for an OpenVSP geometry model.

The paper is organized as follows. Section II gives a brief review of various definitions of equivalent area and their relationships. Section III describes the feasibility analysis/design process by using the notational $100 \mathrm{ft}$ demonstrator concept as an example. Necessary post-design verification analyses (such as grid sensitivity analysis and off-track sonic boom analysis) are also described in section III.

\section{Various Definitions of Equivalent Area}

Traditional sonic boom analysis uses equivalent area defined by Mach angle cuts of the surface pressure and volume distributions of a supersonic configuration. ${ }^{48}$ This traditional approach gradually evolved from using linear methods for estimating surface pressure distributions to using CFD surface pressure distributions. The resulting equivalent area distribution will be referred to as Mach equivalent area $\left(A_{e, m}\right)$. Mach equivalent area was useful to compute the sonic boom characteristics of the early supersonic fighters or to predict near-field pressure distributions of a slender wing-body configuration in the wind tunnel. Mach angle cuts for a given azimuth angle $\theta$ defines a Mach equivalent area distribution $A_{e, m}(x, \theta)$. If the configuration is not a body of revolution, $A_{e, m}(x, \theta)$ varies as the azimuth angle changes. The relationship between $A_{e, m}$ and near-field pressure distribution of a supersonic configuration at azimuth angle $\theta$ can be established by using Whitham's F-function: ${ }^{49}$

$$
F(x, \theta)=\frac{1}{2 \pi} \int_{0}^{x} \frac{A_{e, m}(t, \theta)^{\prime \prime}}{\sqrt{x-t}} d t
$$


where $A_{e, m}(t, \theta)^{\prime \prime}$ is the second derivative of $A_{e, m}(t, \theta)$ with respect to $t$. Whitham's F-function is approximately proportional to the non-dimensional pressure $d p / p$ along the flow direction:

$$
(d p / p)(x, \theta) \approx \frac{\gamma M^{2} F(x-\delta \beta, \theta)}{\sqrt{2 \delta \beta}}
$$

where $\gamma$ is the specific heat ratio, $\delta$ is the distance from the pressure location at azimuth angle $\theta$ to the configuration, $M$ is the free-stream Mach number, and $\beta$ is the Prandtl-Glauert factor $\sqrt{M^{2}-1}$. Equation (2) predicts that the initial pressure rise location at a distance $\delta$ is approximately at $x=\delta \beta$, assuming the initial pressure rise location on the body is at $x=0$. While Eq. (2) provides a reasonably accurate prediction of $d p / p$ of a supersonic configuration for the front part of the pressure signature, the prediction for the aft pressure distribution is usually inaccurate.

The current state-of-the-art sonic boom analysis uses a CFD off-body pressure distribution and propagates the CFD pressure to the ground using the augmented Burgers' equation. Even though there is no theoretical criterion for the distance $\delta$, a standard practice is to use an off-body distance of at least three body lengths away from the configuration. In this paper, all off-body pressure distributions for sonic boom propagation are calculated at $3 \mathrm{BL}$ away from the configuration.

Whitham's F-function formula leads to an integral representation of $A_{e, m}(x, \theta)$ in terms of $F(x, \theta)$ :

$$
A_{e, m}(x, \theta)=4 \int_{0}^{x} F(t, \theta) \sqrt{x-t} d t
$$

Using Eqs. (2) and (3), one can obtain the following integrated equivalent area from off-body pressure distribution:

$$
A_{e, i}(x, \theta)=4 \frac{\sqrt{2 \delta \beta}}{\gamma M^{2}} \int_{0}^{x}(d p / p)\left(t+x_{\theta, \delta}, \theta\right) \sqrt{x-t} d t
$$

where $x_{\theta, \delta}$ is the initial pressure rise location of $(d p / p)(x, \theta)$. In general, $x_{\theta, \delta}$ is noticeably different from $\delta \beta$, predicted by Eq. (2). Equation (4) agrees with Eq. (27) in Ref. 19 or Eq. (16) in Ref. 24 if $x_{\theta, \delta}$ is removed.

The integrated equivalent area does not account for nonlinearity of wave propagation from the configuration to the off-body location. Figure 3 shows the under-track $d p / p$ distributions of the configuration in Fig. 1 at four different locations, shifted forward for easy comparison. Note that the distance from the initial pressure rise location to the pressure rise location near $x=50$ is reduced during the propagation from $0.5 \mathrm{BL}$ to $3 \mathrm{BL}$.

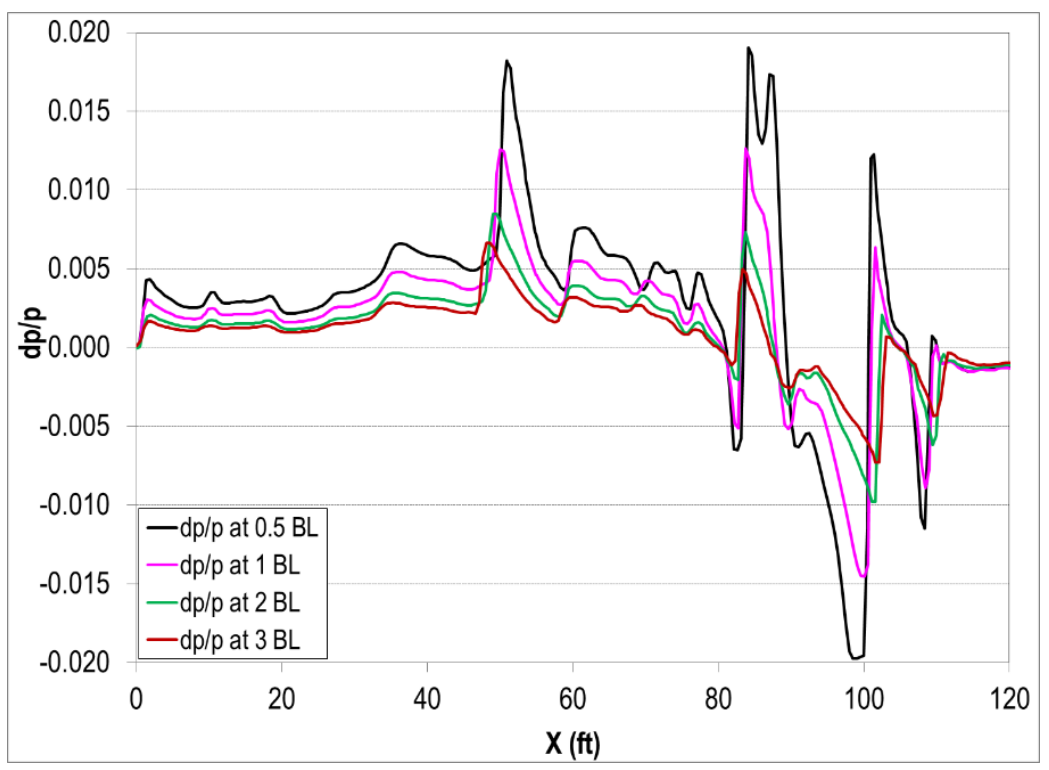

Figure 3. Under-track $d p / p$ at different off-body locations.

American Institute of Aeronautics and Astronautics 
In an attempt to construct a body of revolution whose pressure distribution at a given off-body location is identical to that of the aircraft configuration, the pressure distribution at the off-body location is reversely propagated to a location $\left(\delta_{r}\right)$ closer to the configuration to obtain the reversed pressure distribution $(d p / p)_{r}(x, \theta)$. The rationale is that the reverse propagation via the augmented Burgers' equation is more accurate than linear scaling to predict which body of revolution would generate the $d p / p$ at the off-body location $\delta$. For the same configuration in Fig. 1, the F-functions for the integrated and reversed equivalent areas are given in Fig. 4, which shows that the shock location of the F-function for $A_{e, r}$ near $x=50$ correlates better with the shock location of $d p / p$ at $1 \mathrm{BL}$ than the one for $A_{e, i}$.

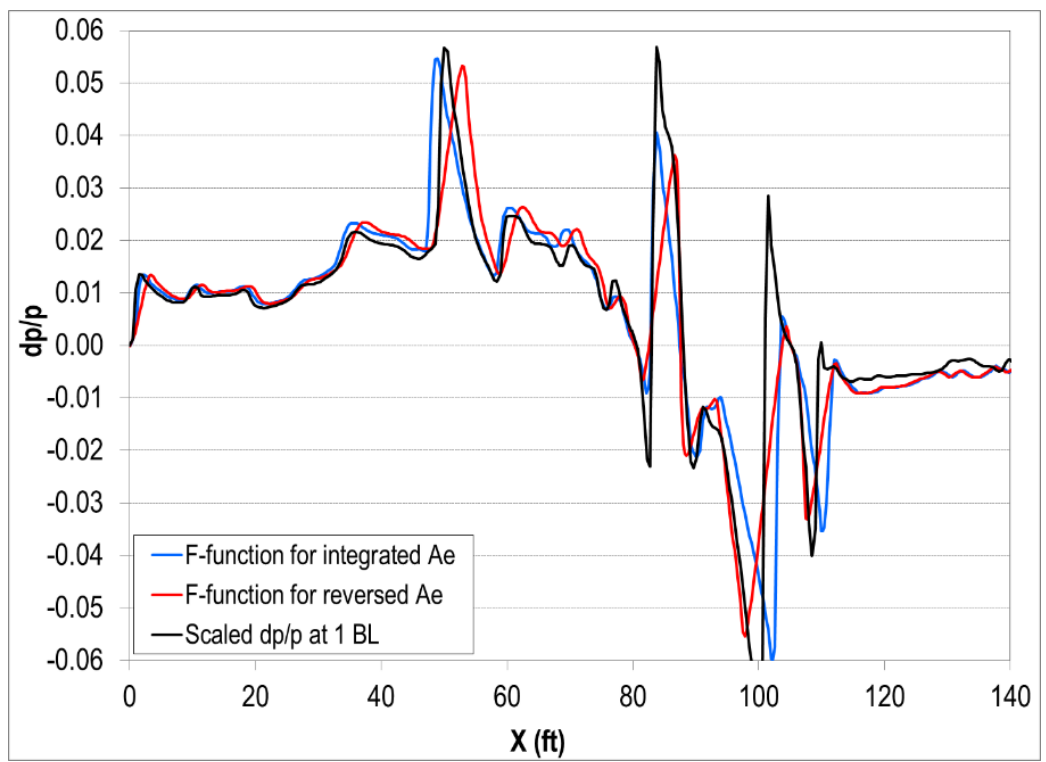

Figure 4. F-functions for the integrated and reserved equivalent areas.

The reversed equivalent area $A_{e, r}(x, \theta)$ is defined similarly as $A_{e, i}(x, \theta):{ }^{29}$

$$
A_{e, r}(x, \theta)=4 \frac{\sqrt{2 \delta_{r} \beta}}{\gamma M^{2}} \int_{0}^{x}(d p / p)_{r}\left(t+x_{\theta, r}, \theta\right) \sqrt{x-t} d t
$$

where $x_{\theta, r}$ is the initial pressure rise location of $(d p / p)_{r}(x, \theta)$. In this paper, $\delta_{r}$ is $50 \mathrm{ft}$ for all reversed equivalent area calculations. Further study is required to identify which body of revolution actually generates the same CFD $d p / p$ at an off-body location $\delta$ as the aircraft configuration.

An important property of the reversed equivalent area is that the change of $A_{e, m}(x, \theta)$ is an accurate first order approximation of the change of $A_{e, r}(x, \theta):{ }^{33}$

$$
A_{e, r}^{\text {design }}(x, \theta) \approx A_{e, r}^{\text {baseline }}(x, \theta)+A_{e, m}^{\text {design }}(x, \theta)-A_{e, m}^{\text {baseline }}(x, \theta)
$$

The right-hand side of Eq. (6) is called the mixed-fidelity reversed $A_{e} \cdot{ }^{33}$ Equation (6) was successfully applied to volume and lift shaping to generate low-boom supersonic concepts using CFD analysis of $d p / p$ at $3 \mathrm{BL} .{ }^{33}$ It was also used to generate low-boom targets for $A_{e, r}$ that implicitly include a flight trim constraint. ${ }^{37}$ Again the formula will be used implicitly in this paper to determine whether a given configuration is feasible to be shaped into a trimmed lowboom design.

Note that Eq. (6) can also be applied to $A_{e, i}$ instead of $A_{e, r}$ to obtain the fixed-fidelity integrated $A_{e}$. An analysis of equivalent areas for wing camber change of a 100ft configuration (see Fig. 5) can provide some intuition on the differences between $A_{e, i}$ and $A_{e, r}$. The analysis results are plotted in Figs. 6 and 7. The mixed-fidelity reversed $A_{e}$ is a much better prediction for $A_{e, r}$ than the corresponding one for $A_{e, i}$ in this case, i.e., the differences between the 
mixed-fidelity and actual reversed equivalent areas are much smaller than the ones between the mixed-fidelity and actual integrated equivalent areas. Other cases studied so far have shown similar trends.

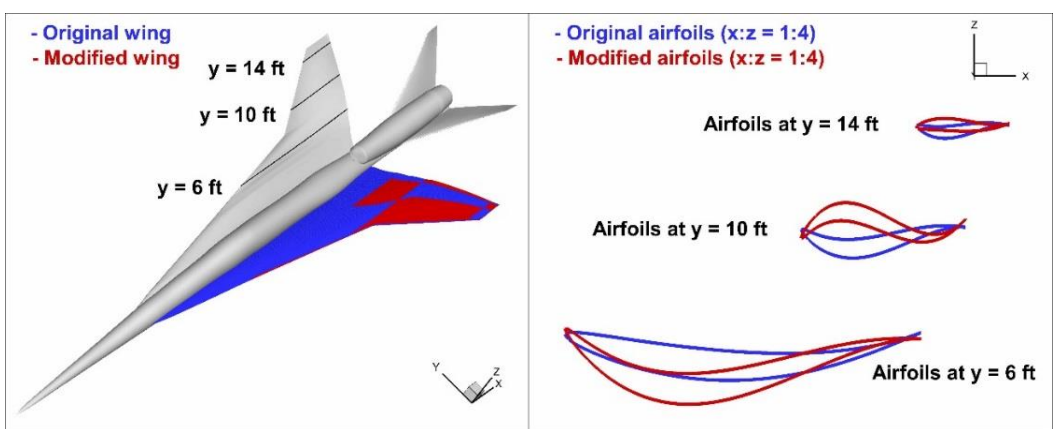

Figure 5. Original wing (blue color) vs modified wing (red color).

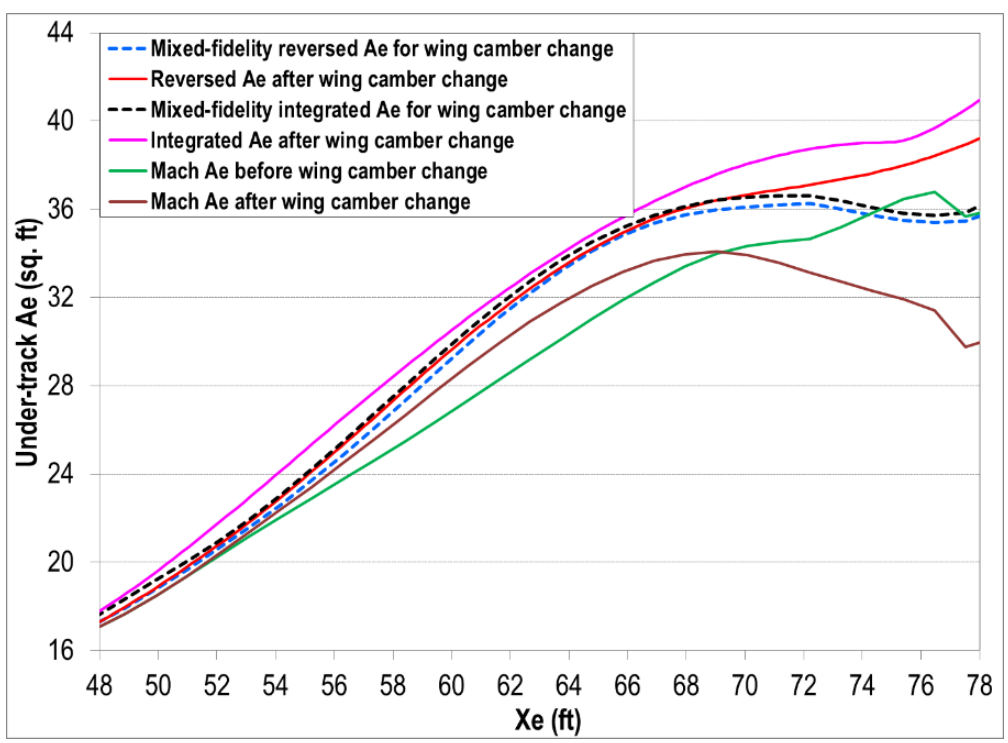

Figure 6. Comparison of under-track equivalent areas for wing camber change.

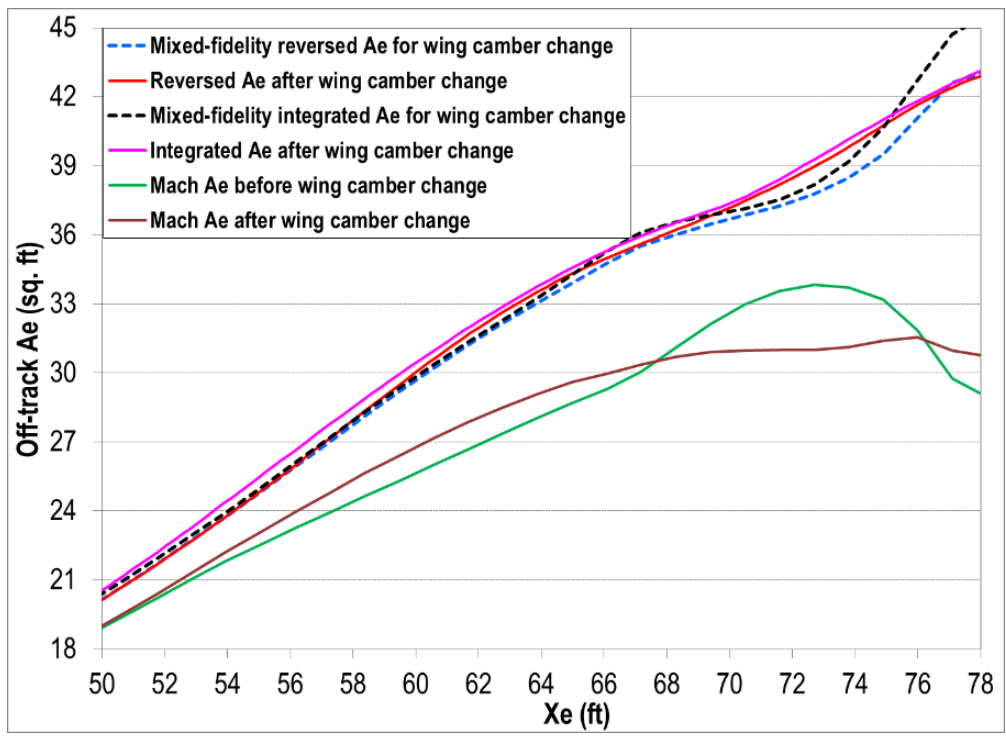

Figure 7. Comparison of off-track equivalent areas (with off-track angle of $35 \mathrm{deg}$ ) for wing camber change.

American Institute of Aeronautics and Astronautics 


\section{Feasibility Analysis/Design Process}

The complete feasibility analysis/design process including both low-boom and flight trim constraints can be illustrated by the following diagram:

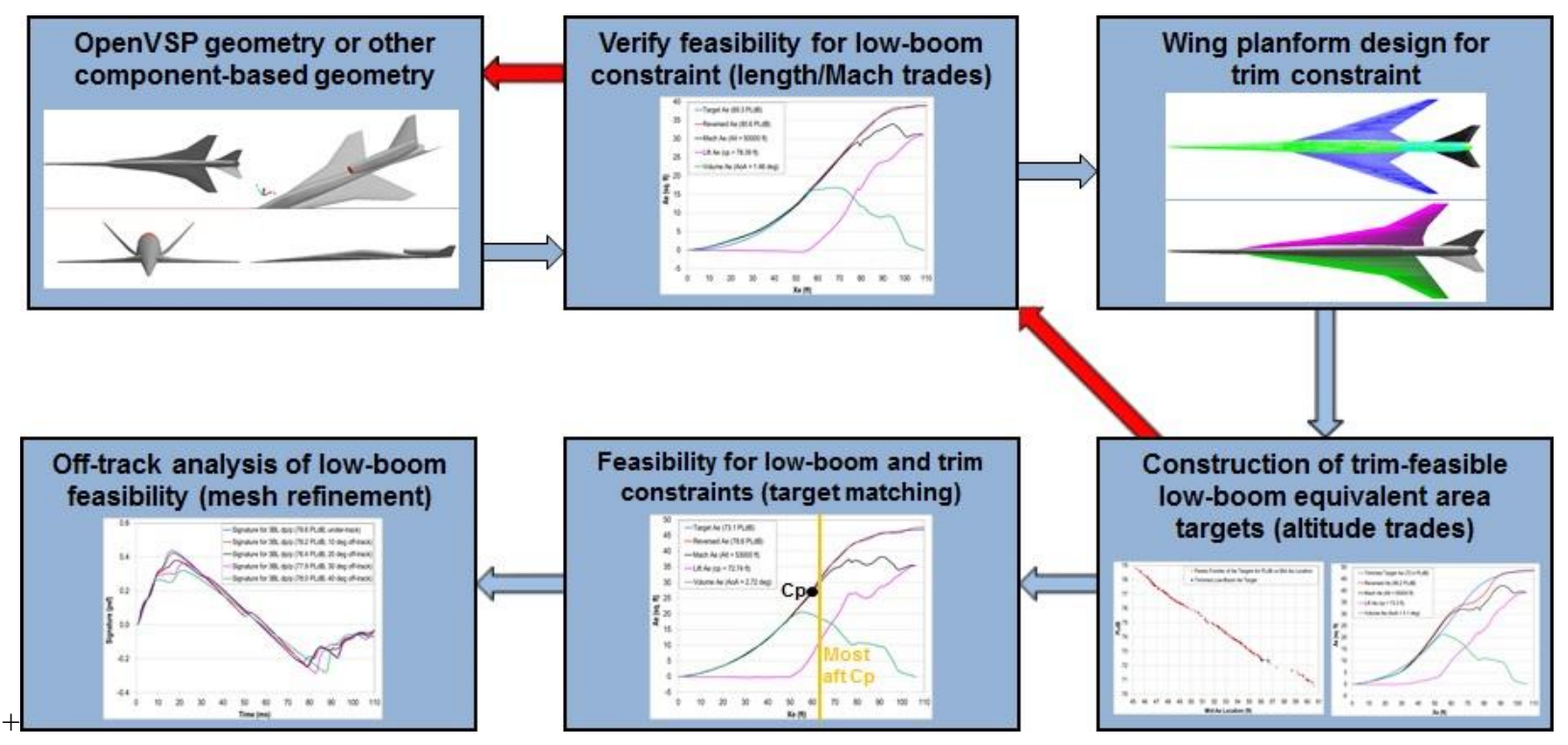

Figure 8. Diagram of feasibility analysis/design process.

The blue arrow is the path for successfully meeting the design goal, while the red arrow is the path for detection of infeasibility. Two critical trades during this process are (1) length/Mach trades for the low-boom constraint and (2) altitude trades for the best low-boom target under the flight trim constraint. Recall that the flight trim constraint is implemented by forcing the $\mathrm{CP}$ at the cruise condition to be ahead of the most aft CG location. The most aft CG location is based on how far back the CG of the configuration can be moved by moving fuel during each flight phase. The flight trim constraint allows the vehicle to maintain the same low-boom shape for trimmed flight during the cruise. A low-boom $A_{e, r}$ target means that the perceived loudness level of its ground signature is significantly lower than the goal PLdB level. In this paper, the goal PLdB level is 75 PLdB. The actual target PLdB value depends on how much uncertainty a designer is willing to endure during concept exploration.

Here is a brief description of the entire concept exploration process. After generating a plausible layout with some practical considerations (such as the sizes of nacelle and cockpit), low-boom targets for $A_{e, r}$ will be generated for the configuration. If the configuration's $A_{e, r}$ can match a low-boom target with relatively small errors (such as less than 3\%) by lift tailoring, then this configuration is considered to be feasible for the requirement of low-boom constraint. Vehicle length or cruise Mach number are effective design variables to achieve the low-boom goal and several iterations might be necessary to achieve a desirable combination. The next step is to determine whether the layout is feasible for a wing planform that satisfies the trim constraint while retaining low-boom characteristics. Here retaining low-boom characteristics means the capability to tailor the lift distribution in the aft part of the configuration. Once such a wing is obtained, a search of optimal cruise altitude is conducted to achieve the lowest boom target for $A_{e, r}$ of the trimmed configuration, while enforcing the trim constraint implicitly in the target by using a surrogate model for predicting the change of CP (see Eq. (7)). If the lowest boom target for $A_{e, r}$ under trim constraint is not quiet enough for the low-boom constraint, then it indicates the infeasibility of this configuration layout to satisfy both low-boom and trim constraints. Significant configuration layout modifications might be required either to improve the feasibility of the trim constraint (such as a forward move of wing planform) or to improve the feasibility of the low-boom constraint (such as an increase of the vehicle length or a reduction of the cruise Mach number). Once a trim-feasible low-boom target for $A_{e, r}$ is achieved, a variety of volume and lift tailoring methods can be used to match the $A_{e, r}$ of the configuration to the low-boom target. Numerous case studies have demonstrated that these methods can tailor the configuration to achieve shaped ground signatures with perceived loudness around $78 \mathrm{PLdB}$. Matching a trim-feasible low-boom target has a minimum effect on the change of the cruise $\mathrm{CP}$ during the shaping process. As a result, the final configuration has similar cruise trim characteristics as the trim-feasible baseline, so it satisfies both low-boom and trim constraints. The final design is reanalyzed by 
using off-track ground signatures as well as refined volume meshes to identify any off-track ground signature degradation or insufficient design mesh resolution issues.

The following subsections include a case study example to demonstrate how to start with a layout that is infeasible for a trimmed low-boom design and develop a trimmed low-boom design by using the process outlined above.

\section{A. Initial Assessment of Feasibility for Low-Boom Constraint}

A 100ft low-boom demonstrator concept was sketched using OpenVSP (see Fig. 9). The design condition was set at a cruise Mach of 1.5 , a cruise weight of $21 \mathrm{~K} \mathrm{lbs}$, and a cruise altitude of $50 \mathrm{~K} \mathrm{ft}$. Under-track $d p / p$ at $3 \mathrm{BL}$ was used to compute the perceived loudness of the ground signature. The low-boom design methods in Refs. 29 and 33 were applied to match $A_{e, r}$ to a low-boom target. The analysis results were summarized in Fig. 10. This configuration was considered to be feasible to achieve a ground signature of 75 PLdB by further shape modifications because of the small gaps between its reversed equivalent area and a low-boom target of 69.3 PLdB.

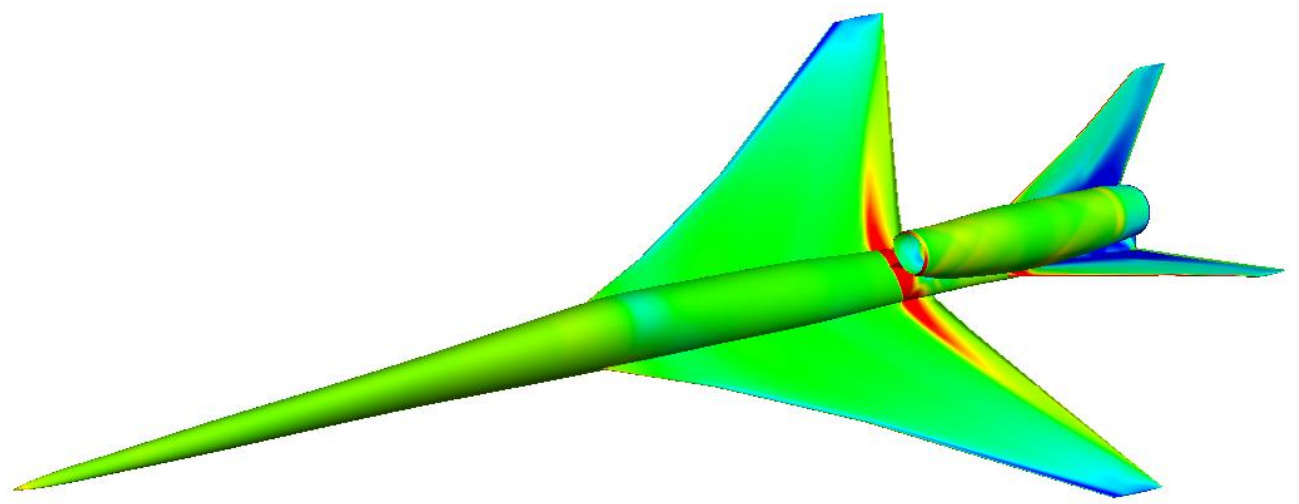

Figure 9. Initial low-boom design without flight trim constraint.

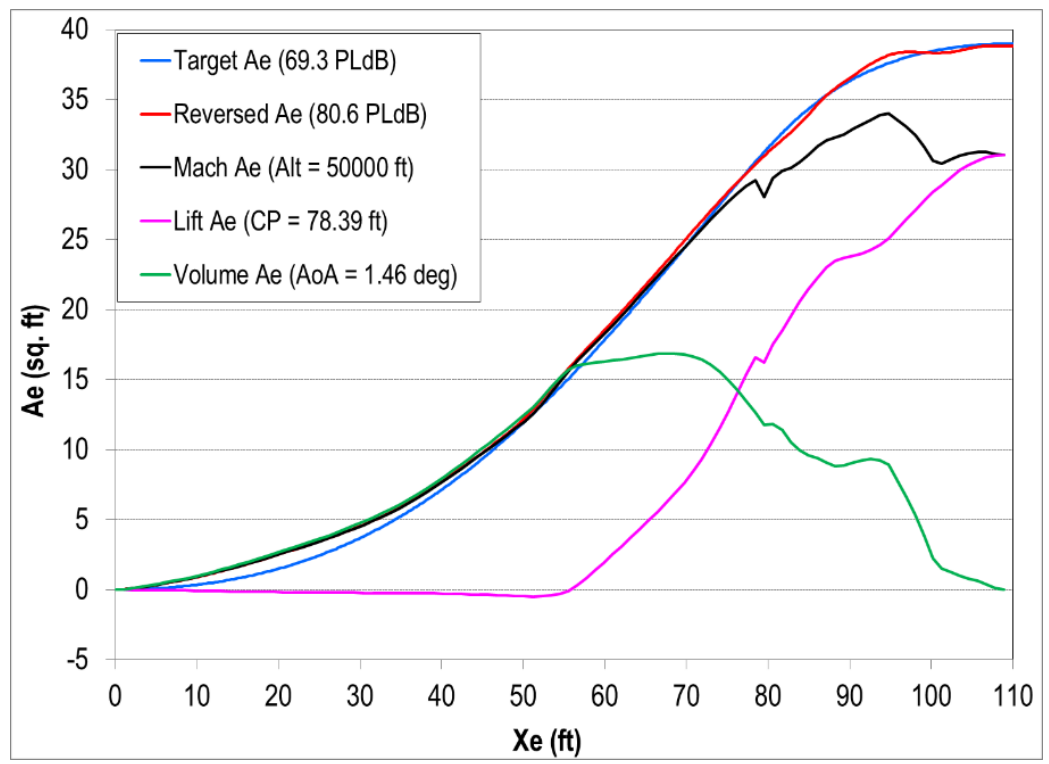

Figure 10. Matching the reversed equivalent area to a low-boom target.

However, the FLOPS estimate of the most aft CG (achievable via fuel pumping) of this configuration is at $x=$ $73.8 \mathrm{ft}$, while CP of this configuration calculated from Cart3D solution is at $x=78.4 \mathrm{ft}$. Here the cruise flight segment is defined by flying at Mach number of 1.5 for $100 \mathrm{nmi}$ at $50 \mathrm{~K} \mathrm{ft}$ in FLOPS analysis. As a result, this configuration must use control surfaces to satisfy the flight trim constraint (i.e., instead of moving fuels, control surfaces must be used to move the $\mathrm{CP}$ to the $\mathrm{CG}$ location during the cruise flight). The use of the control surfaces 
will change the OML of the configuration, which will have an adverse effect on the configuration's low-boom characteristics for the cruise flight. In this example, it is not possible to move the CP forward by $5 \mathrm{ft}$ without significant changes of the wing and/or tail of this configuration. Therefore, this concept was deemed to be infeasible for a trimmed low-boom design.

\section{B. Design of Wing Planform for Flight Trim Constraint}

The most effective approach for moving CP forward is to move the centroid of wing forward. Two constraints are enforced in wing planform exploration: (i) the trailing edge of the root airfoil is a few feet behind the engine inlet to shield the inlet shock and (ii) the trailing edge of the tip airfoil is behind the leading edge of the tail to provide a full range of lift tailoring capability for the aft part of the configuration. Figure 11 includes two wing planform candidates. The top wing is not forward enough to satisfy the flight trim constraint, while the bottom one satisfies the trim constraint. This step was mainly done manually because of the difficulty of selecting a set of wing design variables and their design ranges to generate a desirable wing planform. Several design-of-experiments runs were conducted during the interactive design process to find the feasible wing planform for the flight trim constraint while enabling aft low-boom shaping.

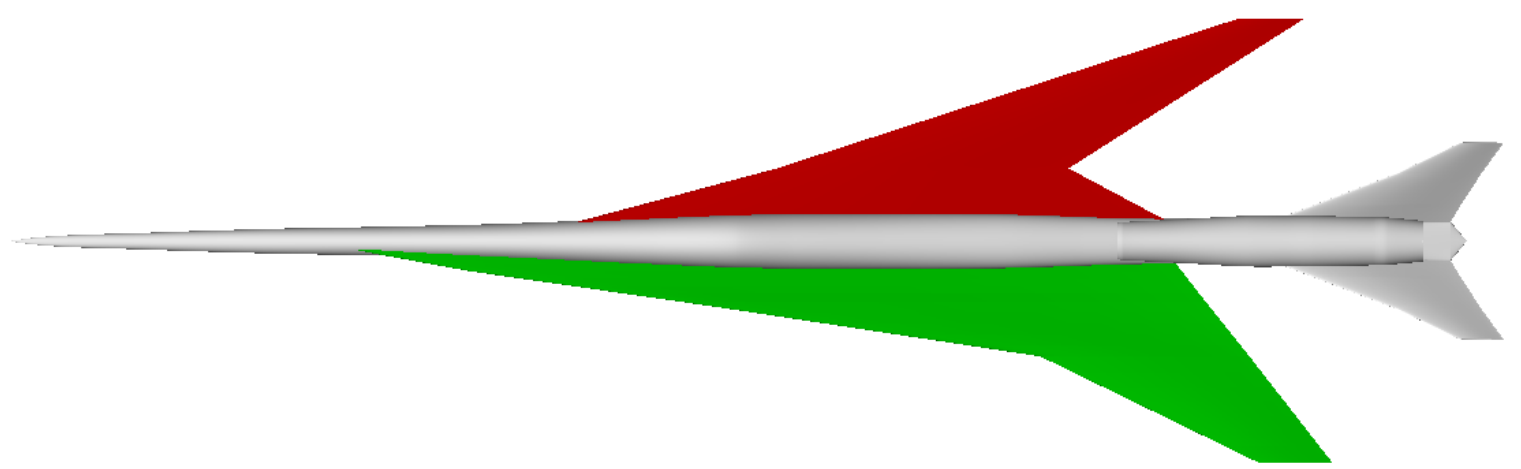

Figure 11. Wing planform (green) improves flight trim while enabling aft low-boom shaping.

The most aft CG for trimmed cruise flight of this configuration with the bottom wing is at $72.5 \mathrm{ft}$, while the CP of the configuration is at $74.0 \mathrm{ft}, 73.5 \mathrm{ft}$, and $73.3 \mathrm{ft}$ for altitudes of $50 \mathrm{~K}, 53 \mathrm{~K}$, and $55 \mathrm{~K} \mathrm{ft}$, respectively. The differences in CP locations are due to different lift coefficients (or angles of attack) at different altitudes for the same cruise weight. As a result, the configuration with the bottom wing in Fig. 11 was selected for low-boom shaping at the cruise altitude of $55 \mathrm{~K} \mathrm{ft}$. The most aft CG location is very influential in a design process to generate a supersonic configuration that satisfies both low-boom and flight trim constraints. The trim constraint violation of $0.8 \mathrm{ft}$ in this case was tolerated because it is less than the uncertainty in the CG location at this stage of the analysis and design process.

\section{Trim-Feasible Low-Boom Target for Reversed Equivalent Area}

The under-track equivalent area analysis results of the down-selected configuration are plotted in Fig. 12. The key question is whether this configuration can be shaped into a low-boom design while maintaining the feasibility for flight trim constraint. The goal is to find a low-boom target such that the gaps between $A_{e, r}$ and its target can be significantly reduced by lift tailoring while not moving $\mathrm{CP}$ aftward. Figure 12 shows a trim-feasible low-boom target for $A_{e, r}$.

The low-boom feasibility is assured by perceived loudness of 72.4 PLdB for the target. The trim feasibility for the low-boom target is enforced by the following constraint:

$$
\frac{\rho_{\infty} U_{\infty}^{2}}{\beta} \int_{x_{0}}^{x_{1}}\left(A_{e, r}^{\mathrm{target}}(t)-A_{e, r}(t)\right)^{\prime} t d t \leq \tau \leq 0
$$

where $x_{0}$ and $x_{1}$ represent the initial and end locations of the nonzero Mach cuts for equivalent area due to lift (see Eq. (3) in Ref. 48 for the relationship between equivalent area due to lift and the lift distribution along the Mach cuts), the azimuth angle symbol $\theta$ is ignored for under-track equivalent areas, $\tau$ controls how strongly the flight trim constraint needs to be enforced, and the superscript outside the parenthesis in Eq. (7) denotes the derivative with respect to $t$. The expression $\frac{\rho_{\infty} U_{\infty}^{2}}{\beta}\left(A_{e, r}^{\text {target }}(x)-A_{e, r}(x)\right)^{\prime}$ provides a good approximation of the potential lift distribution 
changes required to match the target. Therefore, the left term in Eq. (7) represents the potential of CP forward movement after matching the low-boom target. If lift tailoring does generate a design that matches the target, then

$$
\int_{x_{0}}^{x_{1}}\left(A_{e, m}^{\text {design }}(t)-A_{e, m}^{\text {baseline }}(t)\right)^{\prime} t d t \approx \int_{x_{0}}^{x_{1}}\left(A_{e, r}^{\text {design }}(t)-A_{e, r}^{\text {baseline }}(t)\right)^{\prime} t d t \approx \int_{x_{0}}^{x_{1}}\left(A_{e, r}^{\text {target }}(t)-A_{e, r}(t)\right)^{\prime} t d t \leq \frac{\tau \beta}{\rho_{\infty} U_{\infty}^{2}} \leq 0
$$

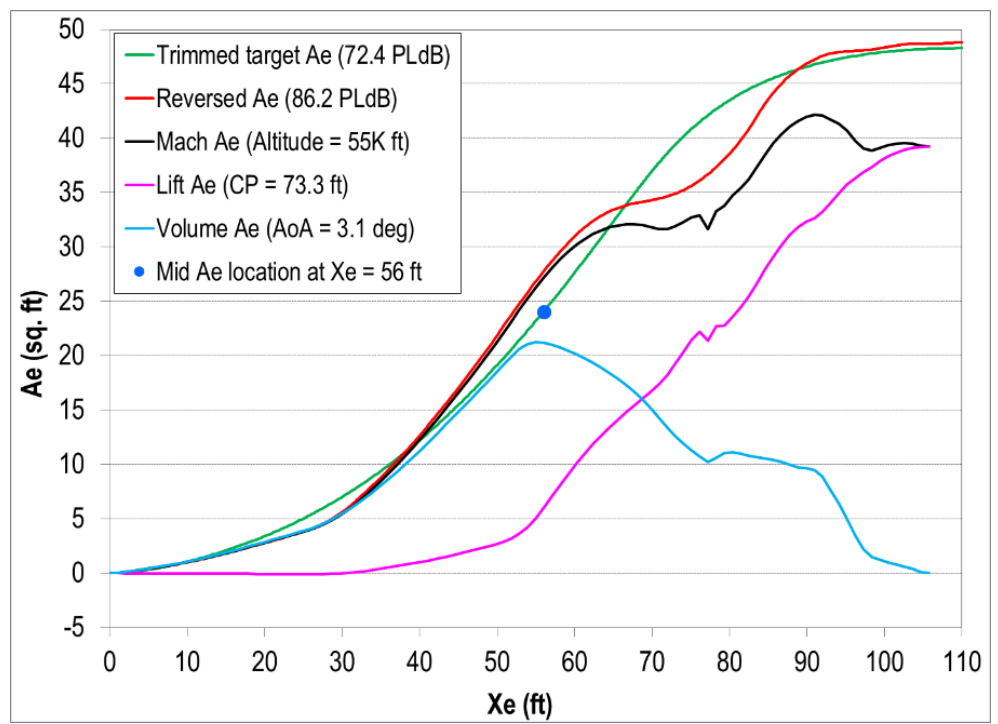

Figure 12. Trim-feasible low-boom target.

In Eq. (8), the first approximation relation follows Eq. (6) and the second is based on the assumption that $A_{e, r}^{\text {design }}$ matches the target. Lift tailoring implies that the change of $A_{e, m}$ is dominated by changes in lift distribution. As a result, $\frac{\rho_{\infty} U_{\infty}^{2}}{\beta}\left(A_{e, m}^{\text {design }}(x)-A_{e, m}^{\text {baseline }}(x)\right)^{\prime}$ is a good approximation of lift distribution changes along the $x$-axis (see Eq. (3) in Ref. 48). Therefore, the first term in Eq. (8) multiplied by $\frac{\rho_{\infty} U_{\infty}^{2}}{\beta}$ is a good approximation of the change of $\mathrm{CP}$ for the design. If this change is negative, the lift tailoring process tends to keep CP of the new design ahead of CP of the baseline, which is desirable for the flight trim constraint. More negative $\tau$ leads to more forward location for CP of the final design.

In practice, one can trade the low-boom constraint and flight trim constraint by using PLdB and the mid $A_{e}$ location of the target using a multi-objective optimization algorithm. Here the mid $A_{e}$ location is the $x_{e}$ location such that its equivalent area is half of the $A_{e}$ value at the end point of the target curve (see Fig. 12). Figure 13 shows the Pareto front of a multi-objective optimization run for trades between PLdB and mid $A_{e}$ location. The trade-off relationship between PLdB and the mid $A_{e}$ location tends to be linear. A simple rule for a trim-feasible target is to pick a Pareto point in Fig. 13 with the smallest mid $A_{e}$ location and PLdB less than 75. Then check whether Eq. (7) is satisfied or not. If not, this is a strong indication that the current configuration is not feasible to satisfy both lowboom and flight trim constraints at the given cruise condition. In the case that one could not find a feasible target, changing the cruise altitude is the easiest option to resolve the conflict between low-boom and flight trim constraints because it will change $A_{e, r}$ of the current configuration and lead to different low-boom targets. If an altitude change does not result in a feasible solution, then one has to reconsider a reduced cruise Mach number or an increase of the vehicle length to satisfy the low-boom and flight trim constraints. For this example, the optimal target with mid $A_{e}$ location at $56 \mathrm{ft}$ in Fig. 12 satisfies Eq. (7) with $x_{0}=33 \mathrm{ft}, x_{1}=105 \mathrm{ft}$, and $\tau=0$. So this configuration has the potential to satisfy both low-boom and flight trim constraints for a cruise Mach number of 1.5 , a cruise weight of $21 \mathrm{~K} \mathrm{lbs}$, and a cruise altitude of $55 \mathrm{~K} \mathrm{ft}$. Note that the CP of the configuration is at $x=73.3 \mathrm{ft}$, which is still behind the most aft CG at $x=72.5 \mathrm{ft}$. Due to uncertainty in the estimation of CP location using equivalent areas, the flight trim constraint is not strictly enforced at the moment. The margin in PLdB of the target can be used to trade for trim margin later in the process. 


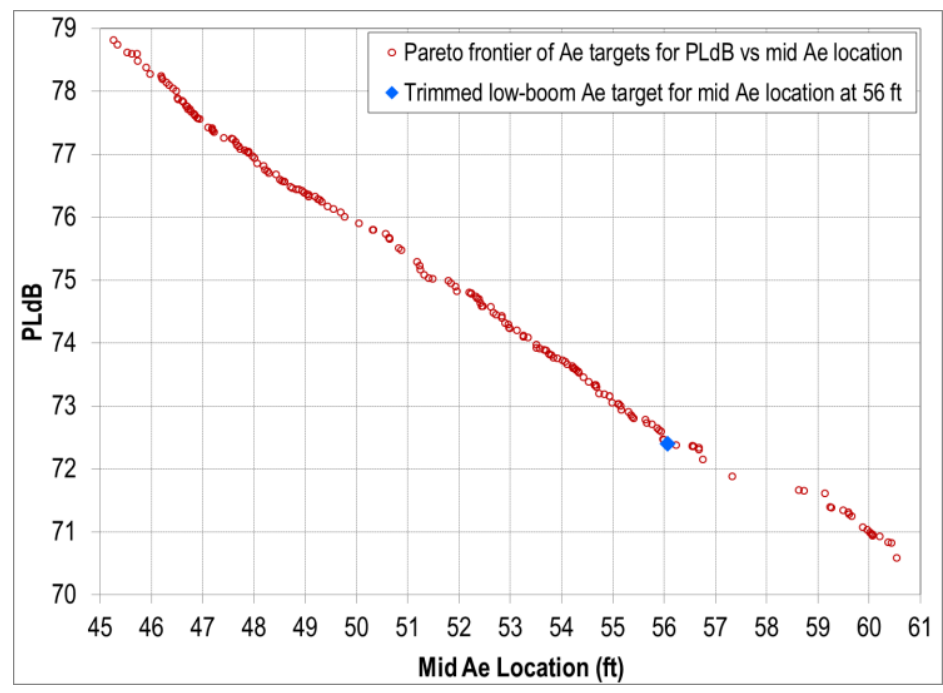

Figure 13. Searching for a trim-feasible low-boom target.

\section{Matching Trim-Feasible Low-Boom Target}

The design method using mixed-fidelity equivalent $\operatorname{area}^{33}$ was used to match $A_{e, r}$ of the configuration to the selected target. The wing and tail camber surfaces were remodeled as parametric geometry shapes with 9 and 5 design variables, respectively, using the shape morphing tool PROTEUS. ${ }^{44}$ To match the mixed-fidelity equivalent area to the target, a numerical optimization was performed using 14 design variables and CFD surface pressure solutions.. The matching result is shown in Fig. 14.

The angle of attack was fixed during the low-boom shaping process. If the resulting configuration has a very different lift coefficient than the baseline, one can either change the angle of attack to obtain the required lift coefficient or change the cruise altitude to regain the total lift required for the cruise weight $(21 \mathrm{~K} l \mathrm{bs}$ in this case). Moreover, reanalyzing the configuration at different altitudes provides an opportunity to identify the optimal altitude for satisfying the low-boom constraint. In this case, after the lift tailoring, the optimal low-boom altitude is $53 \mathrm{~K} \mathrm{ft}$ and the reversed equivalent area for the configuration is included in Fig. 14. Unlike $A_{e, m}$, that has a fixed end value for the given altitude and cruise weight, $A_{e, r}$ usually has different end values as the configuration shape changes. This might require some modifications of the target equivalent area during the low-boom shaping process. Because the end value of $A_{e, r}$ for the current configuration is noticeably different from the previous one (see Fig. 14), a new low-boom target is generated to improve the low-boom characteristics of the current design (see Fig. 15).

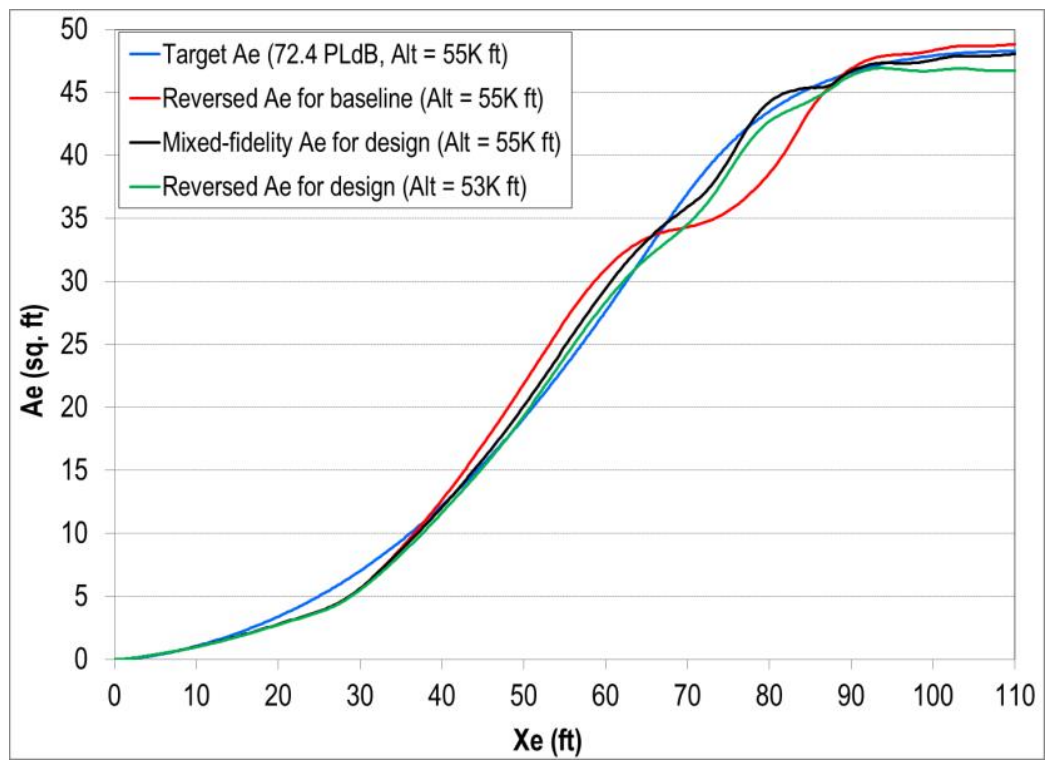

Figure 14. Equivalent area analysis after inverse design using mixed-fidelity equivalent area.

11

American Institute of Aeronautics and Astronautics 
In general, lift tailoring is considered to be completed once the gaps between $A_{e, r}$ and a low-boom target are small enough to be eliminated by volume shaping. Afterward, the fuselage volume shaping method ${ }^{29}$ can be applied to match $A_{e, r}$ to a low-boom target, followed by aft signature shaping. ${ }^{32}$ The equivalent area analysis results for the final design are included in Fig. 15.

The final design is considered to be feasible for the low-boom constraint (i.e., it has the potential to have an under-track ground signature less than 75 PLdB after minor shape modifications using more advanced inverse design methods, such as CFD adjoint design methods). The FLOPS estimate of the most aft CG for the final design is at $x=73.1 \mathrm{ft}$ and the CP from CFD analysis is at $x=72.7 \mathrm{ft}$. Therefore, the final design is also feasible for the flight trim constraint.

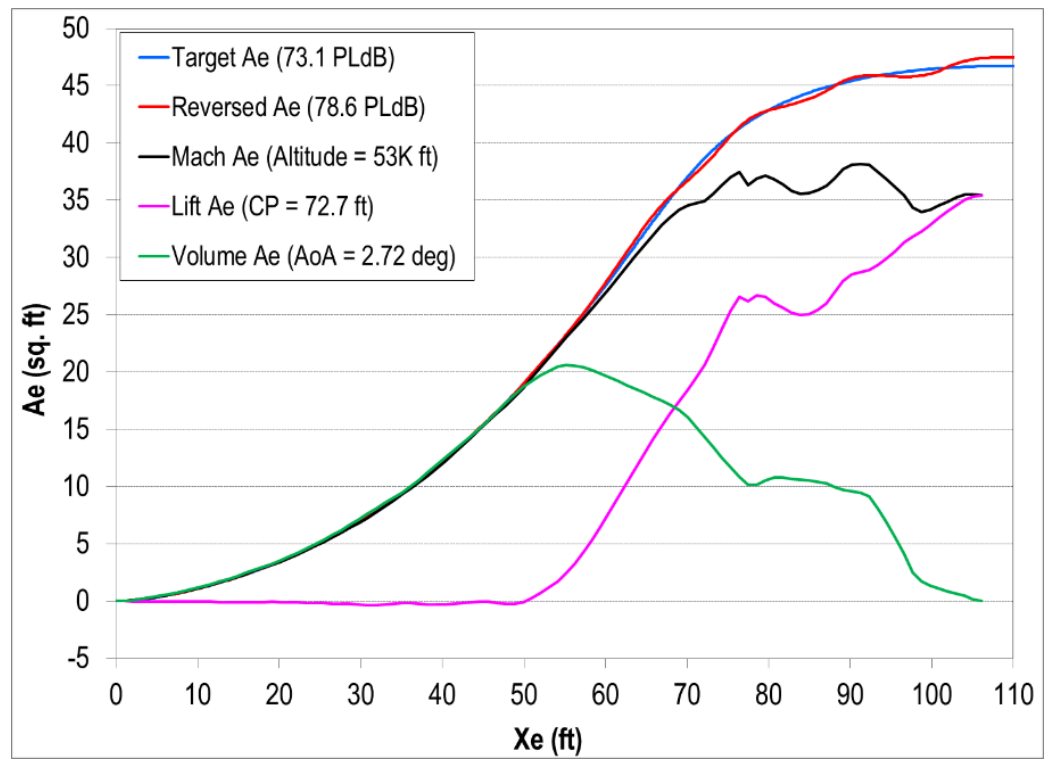

Figure 15. Equivalent area analysis of the final design.

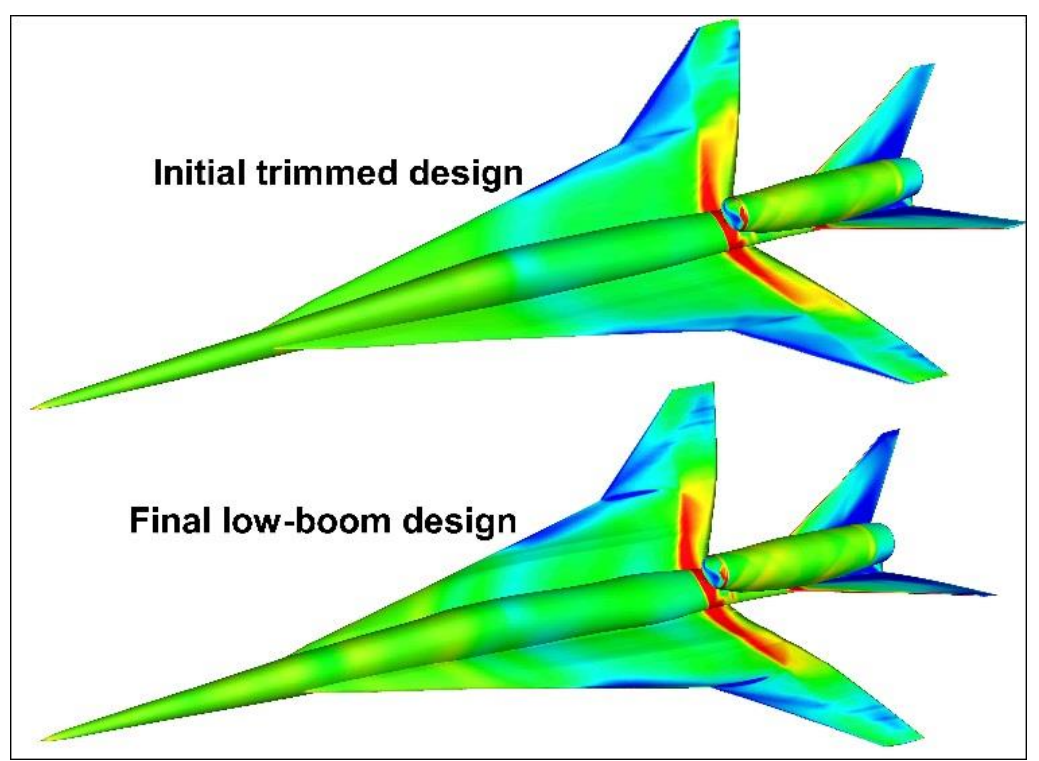

Figure 16. Comparison of the initial trimmed design and final low-boom design.

The most significant design changes from the initial trimmed design to the final low-boom design are the camber surfaces for wing and tail, as well as the thickening of the front part of fuselage to fill the equivalent area gaps ahead of $x_{e}=33 \mathrm{ft}$ (where the lift distribution has no influence). See Fig. 16 for a comparison of the CFD surface pressure contours of these two configurations. Without any explicit constraint on the CP location during the low-boom 
shaping process, the CP location ( $72.7 \mathrm{ft})$ of the final design is ahead of that $(73.3 \mathrm{ft})$ of the initial trimmed design. Thus, the final design improves the flight trim margin of the baseline because the camber surface modifications have an insignificant effect on the CG.

\section{E. Post-Design Analyses}

The final design was reanalyzed for its under-track ground signature using a refined volume mesh of $64 \mathrm{M}$ cells (instead of the design mesh of $23 \mathrm{M}$ cells) for Cart3D. The two under-track signatures corresponding to $d p / p$ computed from the design mesh and the refined analysis mesh have the same PLdB value of 78.6 with some insignificant differences in their shapes (see Fig. 17).

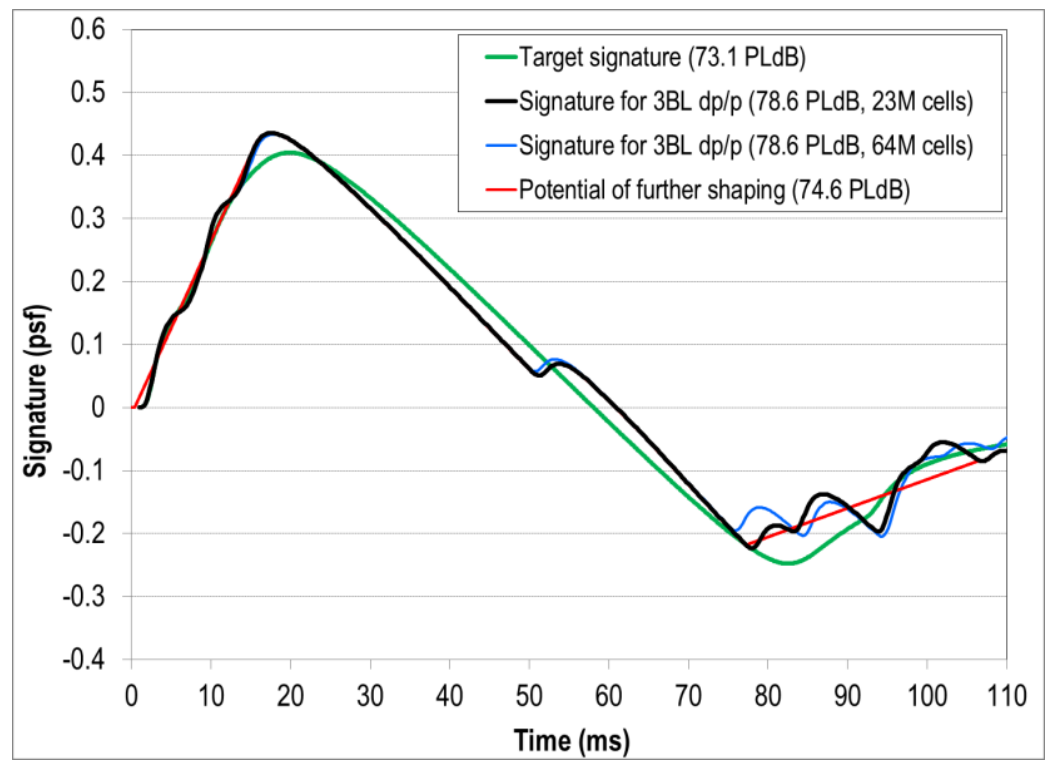

Figure 17. Reanalysis of the final design with a refined mesh.

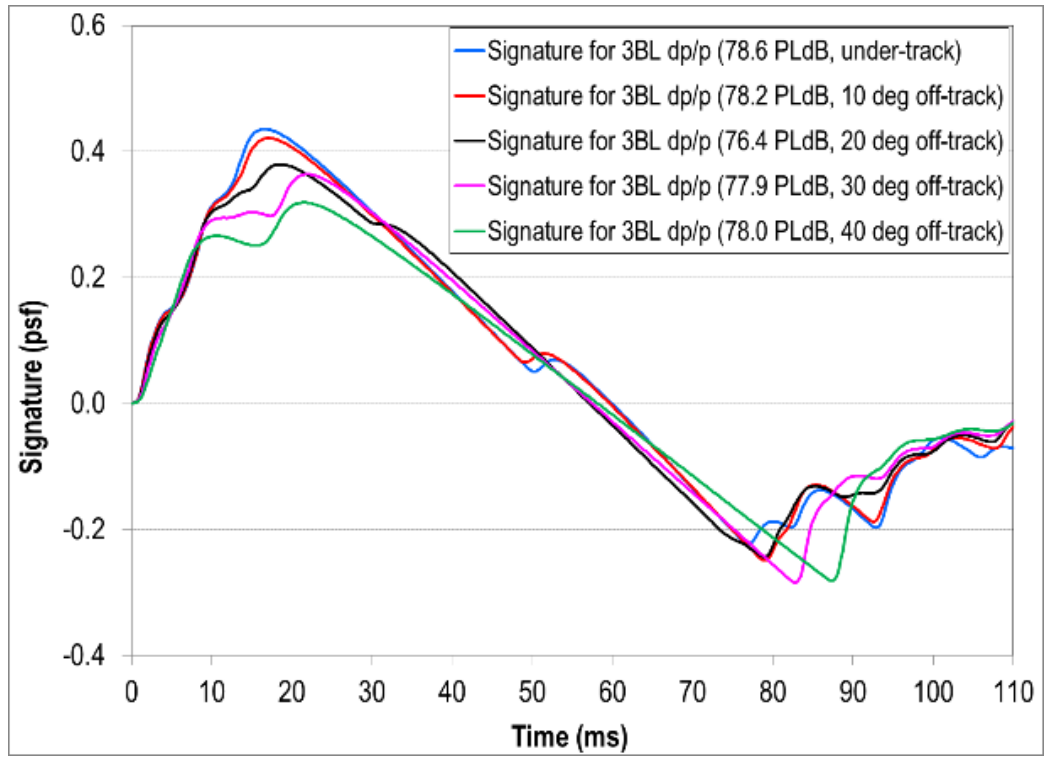

Figure 18. Off-track ground signatures of the final low-boom design.

To understand how small oscillations in the ground signature affect its PLdB value, the front and aft parts of the ground signature of the final design are replaced by the two red line segments in Fig. 17. The resulting ground signature is constructed from three curves: the front [red] linear segment, the [black] ground signature from 18 to 78

13

American Institute of Aeronautics and Astronautics 
ms, and the aft [red] linear segment. The loudness calculation shows that this signature has a PLdB value of 74.6. This analysis highlights two uncertainty issues in development of a low-boom flight demonstrator. First of all, small oscillations of the ground signature of the final design along the two red line segments increase its PLdB value by 4 . Secondly, assume that one could further shape the configuration so that its ground signature would match the constructed ground signature of 74.6 PLdB and achieve the low-boom goal. However, due to uncertainty in the propagation model and atmospheric disturbances, the measured ground signature during the flight test might have small oscillations. These small oscillations could make the measured groud signature much louder than the predicted 74.6 PLdB. The sensitivity of PLdB with respect to small oscillations in the ground signature shape increases the uncertainty in achieving a low-boom loudness target for a demonstrator project.

Achieving a trim-feasible low-boom design is a critical step in developing a low-boom flight demonstrator, but a low-boom flight demonstrator has many other constraints that are not considered in this paper (such as fuselagewing volume for landing gear). In terms of design method development, the next challenge is to develop a systematic process that allows low-boom shaping for ground signatures at all off-track angles. In this paper, offtrack ground signatures for the final design were calculated to understand the low-boom characteristics at selected off-track locations. The under-track ground signature has the highest PLdB value among all calculated ground signatures (see Fig. 18). Further design improvement to reduce the loudness of the under-track ground usually requires very localized shape changes (to eliminate the small oscillations in the ground signature) and tends to have adverse effects on off-track ground signatures. Novel methods are needed to achieve simultaneous improvements of low-boom characteristics at all off-track angles.

\section{Concluding Remarks}

Tremendous advances in research related to low-boom supersonic configurations have led NASA to investigate the potential for developing a low-boom supersonic demonstrator. Such a demonstrator can be used for community response testing to establish a database for the international community to consider in the development of new sonic boom regulations. However, effective exploration of the entire design space (including OML geometry, cruise Mach number, vehicle length, and cruise altitude) for a low-boom supersonic flight demonstrator is still a challenge. An analysis/design process is proposed to develop a supersonic configuration that is feasible to have a ground signature with perceived loudness less than the PLdB noise goal and simultaneously have a trimmed cruise flight.

The most important feature of the proposed analysis/design process is an early detection of infeasible configuration layouts to satisfy both low-boom and flight trim constraints. The paper focuses on providing some insight on how to include cruise Mach number, vehicle length, and cruise altitude in the concept exploration process and how to use them to satisfy both low-boom and flight trim constraints. The flight trim constraint is implicitly included in the low-boom target for reversed equivalent area. A trim-feasible low-boom target allows designers to shape a configuration for a low-boom constraint only, because the process automatically enforces the flight trim constraint. The validity of the trim constraint is based on an approximation relationship between the derivative of reversed equivalent area and lift distribution along the $x$-axis. This process was shown in the example of a notional $100 \mathrm{ft}$ flight demonstrator concept.

\section{Acknowledgement}

The author would like to thank Karl Geiselhart at NASA Langley Research Center for his help in developing the initial OpenVSP demonstrator concept and providing FLOPS estimate of the most aft CG for trimmed cruise flight.

\section{References}

${ }^{1}$ Howe, D., "Hybrid CART3D/OVERFLOW Near-Field Analysis of a Low Boom Configuration with Wind Tunnel Comparisons," AIAA-2011-3336, June 2011.

${ }^{2}$ Carter, M., Campbell, R., and Nayani, S., "USM3D Analysis of Low Boom Configuration," AIAA-2011-3335, June 2011.

${ }^{3}$ Park, M., "Low Boom Configuration Analysis with FUN3D Adjoint Simulation Framework," AIAA-2011-3337, June 2011. 
${ }^{4}$ Elmiligui, A., Cliff, S., Wilcox, F., Nemec, M., Bangert, L., Aftosmis, M., and Parlette, E., "Sonic Boom Computations for a Mach 1.6 Cruise Low Boom Configuration and Comparisons with Wind Tunnel Data," AIAA2011-3496, June 2011.

${ }^{5}$ Ishikawa, H., Makino, Y., and Ohira, K., "Sonic-Boom Prediction of a Scaled Low-Boom Demonstration Aircraft Considering Viscosity Effects," AIAA-2011-3662, June 2011.

${ }^{6}$ Waithe, K., "Introduction of First Low Boom Prediction Workshop," AIAA-2013-0650, January 2013.

${ }^{7}$ Durston, D., Elmiligui, A., Cliff, S., Winski, C., Carter, M., and Walker, E., "Experimental and Computational Sonic Boom Assessment of Boeing N+2 Low Boom Models," AIAA-2014-2140, June 2014.

${ }^{8}$ West, T., Reuter, B., Walker, E., Kleb, B., and Park, M., "Uncertainty Quantification and Certification Prediction of Low-Boom Supersonic Aircraft Configurations (Invited),” AIAA-2014-2139, June 2014.

${ }^{9}$ Silva, W., Garza, A., Zink, S., Bounajem, E., Johnson, C., Buonanno, M., Sanetrik, M., Chwalowski, P., Yoo, S., and Hur, J., "An Overview of the NASA High Speed ASE Project: Aeroelastic Analyses of a Low-Boom Supersonic Configuration," AIAA- 2015-0684, January 2015.

${ }^{10}$ Campbell, R., and Nayani, S., "Unstructured Grids for Sonic Boom Analysis and Design," AIAA- 2015-1250, January 2015.

${ }^{11}$ Durston, D., Cliff, S., Wayman, T., Merret, J., Elmiligui, A., and Bangert, L., "Near-Field Sonic Boom Test on Two Low-Boom Configurations Using Multiple Measurement Techniques at NASA Ames," AIAA-2011-3333, June 2011.

12 Wayman, T., Waithe, K., Howe, D., Bangert, L., and Wilcox, F., "Near Field Acoustic Test on a Low Boom Configuration in Langley's 4x4 Wind Tunnel," AIAA-2011-3331, June 2011.

${ }^{13}$ Wayman, T., Hicks, J., and Merret, J., "Force and Moment Test on a Low Boom Configuration in Glenn's 8 x 6 Wind Tunnel," AIAA-2011-3332, June 2011.

${ }^{14}$ Waithe, K., "Design of a Wind Tunnel Mount for a Low Boom Test," AIAA-2011-3334, June 2011.

15 Morgenstern, J., Buonanno, M., and Nordstrud, N., "N+2 Low Boom Wind Tunnel Model Design and Validation," AIAA-2012-3217, June 2012.

${ }^{16}$ Morgenstern, J., "How to Accurately Measure Low Sonic Boom or Model Surface Pressures in Supersonic Wind Tunnels," AIAA-2012-3215, June 2012.

${ }^{17}$ Morgenstern, J., “Distortion Correction for Low Sonic Boom Measurement in Wind Tunnels,” AIAA-2012-3216, June 2012.

${ }^{18}$ Geiselhart, K., Ozoroski, L., Fenbert, J., Shields, E., and Li, W., "Integration of Multifidelity Multidisciplinary Computer Codes for Design and Analysis of Supersonic Aircraft," AIAA-2011-0465, January 2011.

${ }^{19}$ Alonso, J., and Colonno, M., "Multidisciplinary Optimization with Applications to Sonic-Boom Minimization," Annual Review of Fluid Mechanics, Vol. 44, Jan., 2012, pp. 505-526.

${ }^{20}$ Wintzer, M. and Kroo, I., "Optimization and Adjoint-Based CFD for the Conceptual Design of Low Sonic Boom Aircraft," AIAA-2012-0963, January 2012.

${ }^{21}$ Minelli, A., Din, I., and Carrier, G., "Advanced Optimization Approach for Supersonic Low-Boom Design," AIAA-2012-2168, June 2012.

${ }^{22}$ Morgenstern, J., “Optimum Signature Shaping for Low Sonic Boom,” AIAA-2012-3218, June 2012.

${ }^{23}$ Lukaczyk, T., Palacios, F., and Alonso, J., "Response Surface Methodologies for Low-Boom Supersonic Aircraft Design using Equivalent Area Distributions," AIAA-2012-5705, September 2012.

${ }^{24}$ Palacios, F., Alonso, J., Colonno, M., Hicken, J., and Lukaczyk, T., “Adjoint-Based Method for Supersonic Aircraft Design Using Equivalent Area Distributions," AIAA-2012-0269, 2012.

${ }^{25}$ Minelli, A., Din, I., Carrier, G., Zerbinati, A., and Desideri, J., "Cooperation and Competition Strategies in Multiobjective Shape Optimization - Application to Low-boom/Low-drag Supersonic Business Jet,” AIAA-2013-2648, June 2013.

${ }^{26}$ Minelli, A., Din, I., and Carrier, G., "Inverse Design Approach for Low-Boom Supersonic Configurations," AIAA Journal, Vol. 52, No. 10, 2014, pp. 2198-2212.

${ }^{27}$ Wintzer, M., Castner, R., and Geiselhart, K., "Airframe-Nozzle-Plume Interactions in the Context of Low Sonic Boom Design," AIAA-2015-1045, January 2015.

${ }^{28} \mathrm{Li}, \mathrm{W}$., and Shields, E., "Generation of Parametric Equivalent-Area Targets for Design of Low-Boom Supersonic Concepts,” AIAA-2011-0462, January 2011.

${ }^{29} \mathrm{Li}$, W., and Rallabhandi, S., "Inverse Design of Low-Boom Supersonic Concepts Using Reversed Equivalent Area Targets," AIAA-2011-3498, June 2011. Journal of Aircraft, Vol. 51, No. 1, 2014, pp. 29-36.

${ }^{30}$ Rallabhandi, S., "Sonic Boom Adjoint Methodology and its Applications," AIAA-2011-3497, June 2011.

31 Aftosmis, M., Nemec, M., and Cliff, S., “Adjoint-Based Low-boom Design with Cart3D,” AIAA-2011-3500, June 2011. 
${ }^{32}$ Ordaz, I., and Li, W., "Adaptive Aft Signature Shaping of a Low-Boom Supersonic Aircraft Using Off-Body Pressures," AIAA-2012-0020, January 2012.

${ }^{33}$ Ordaz, I., and Li, W., "Using CFD Surface Solutions to Shape Sonic Boom Signatures Propagated from Off-Body Pressure," AIAA-2013-2660, June 2013. (accepted for publication in Journal of Aircraft)

${ }^{34}$ Rallabhandi, S., Nielsen, E., and Diskin, B., "Sonic-Boom Mitigation Through Aircraft Design and Adjoint Methodology," AIAA-2012-3220, June 2012. Journal of Aircraft, Vol. 51, No. 2, 2014, pp. 502-510.

${ }^{35}$ Rallabhandi, S., "Application of Adjoint Methodology to Supersonic Aircraft Design Using Reversed Equivalent Areas," AIAA-2013-2663, June 2013. Journal of Aircraft, Vol. 51, No. 6, 2014, pp. 1873-1882.

${ }^{36}$ Rallabhandi, S., "Application of Adjoint Methodology in Various Aspects of Sonic Boom Design," AIAA-20142271, June 2014.

${ }^{37}$ Ordaz, I., Geiselhart, K., and Fenbert, J., "Conceptual Design of Low-Boom Supersonic Aircraft with Flight Trim Requirement," AIAA-2014-2141, June 2014.

${ }^{38}$ Shields, E., and Li, W., "CFD-Based Redesign of a Low-Boom Supersonic Demonstrator Concept," AIAA-20113499, June 2011.

${ }^{39}$ Berger, C., Carmona, K., Espinal, D., Im, H., and Zha, G., "Supersonic Bi-Directional Flying Wing Configuration with Low Sonic Boom and High Aerodynamic Efficiency," AIAA-2011-3663, June 2011.

${ }^{40}$ Magee, T., Shaw, S., and Fugal, S., "Experimental Validations of a Low-Boom Aircraft Design," AIAA-2013-0646, January 2013.

${ }^{41}$ Morgenstern, J., Buonanno, M., and Marconi, F., "Full Configuration Low Boom Model and Grids for 2014 Sonic Boom Prediction Workshop," AIAA-2013-0647, January 2013.

${ }^{42}$ McCuller, L., "FLOPS User Guide," NASA Langley Research Center, Hampton, Virginia, 2008.

${ }^{43}$ OpenVSP, http://www.openvsp.org, [cited October 2015].

${ }^{44}$ Li, W., "Rapid Parameterization Schemes for Aircraft Shape Optimization," AIAA-2012-0964, January 2012.

${ }^{45}$ CART3D, http://people.nas.nasa.gov/ aftosmis/cart3d/cart3Dhome.html, [cited October 2014].

${ }^{46}$ Ordaz, I., and Li, W., "Integration of Off-Track Sonic Boom Analysis in Conceptual Design of Supersonic Aircraft," AIAA-2011-0464, January 2011. Journal of Aircraft, Vol. 51, No. 1, 2014, pp. 23-28.

${ }^{47}$ Rallabhandi, S., "Advanced Sonic Boom Prediction Using Augmented Burgers' Equation," AIAA-2011-1278, January 2011.

${ }^{48}$ Plotkin, K., "Review of Sonic Boom Theory," AIAA-1989-1105, April 1989.

${ }^{49}$ Whitham, G., "The Flow Pattern of a Supersonic Projectile," Communications on Pure and Applied Mathematics, Vol. 5, No. 3, 1952, pp. 301-348. 